\title{
0 estranho mundo da informação - e da materialidade - no campo da comunicação
}

\section{Liráucio Girardi Jr}

\section{Resumo}

A presença, cada vez maior, de estudos centrados na materialidade da comunicação trouxe para 0 campo da comunicação dois tipos de abordagem muito particulares. Neste trabalho, vamos nos concentrar na especificidade das novas mídias e no reaparecimento de modelos baseados na teoria da informação de Claude E. Shannon e da cibernética de Norbert Wiener. A convergência entre media technologies e digital computing, indicada por Manovich, trouxe para o campo da comunicação um conjunto de novos problemas de pesquisa ou a reorientação de problemas clássicos que seremos obrigados a enfrentar reflexivamente.

\section{Palavras-Chave}

Informação. Novas Mídias. Materialidade.
Liráucio Girardi Jr I lira.sociologia@gmail.com Doutor em Sociologia pela Universidade de São Paulo - USP, Brasil. Professor de Sociologia da Comunicação na Faculdade Cásper Líbero e USCS. Professor-substituto de Teorias da Comunicação da Universidade Estadual de Campinas - UNICAMP, Brasil (2015-2016).
Gostaríamos de começar nossa reflexão com uma série de questões levantadas por Braga (2006, 2011), Martino (2010, 2013), Albuquerque (2002) e Felinto $(2006,2011)$, uma vez que, direta ou indiretamente, estão associadas a uma questão-chave dos debates epistemológicos contemporâneos sobre a comunicação: qual seria a relação entre as Teorias da Comunicação e as Teorias da Cibercultura? Poderíamos ampliar essa questão para os Media Studies, os Software Studies ou a Comunicação mediada por computador?

No caso de sua integração ao campo da comunicação, esse processo aponta para uma continuidade nas formas de configuração dos problemas de pesquisa considerados comunicacionais? Ou, pelo contrário, eles pressupõem a identificação de novos objetos, abordagens e, consequentemente, novos campos? 0 que seria e o que não seria comunicacional neles?

Reiteradamente, Braga (2004, 2006, 2011) tem procurado mostrar que, embora o campo 
da comunicação seja reconhecido por seu trabalho interdisciplinar, torna-se fundamental - para a construção de sua identidade - 0 desentranhamento de problemas de pesquisa especificamente comunicacionais. Deste modo:

“... 0 objeto da comunicação não pode ser apreendido enquanto 'coisas' nem 'temas', mas sim como um certo tipo de processos epistemicamente caracterizados por uma perspectiva comunicacional (...) Que se busque capturar tais processos e suas características nas mídias, na atualidade, nos signos, em episódios interacionais - não faz tanta diferença" (BRAGA, 2011 p. 6).

Braga direciona essa perspectiva comunicacional para os processos de interação, ou seja, aqueles processos simbólicos e práticos que organizam as trocas entre seres humanos, ao garantir a viabilização de ações e objetivos determinados, e que pressupõem algum tipo de coparticipação, coordenação de esforços, competição ou relações de dominação. No entanto, a sua completa adequação ao campo dos estudos de comunicação pressupõe a sua integração aos processos mediatizados que têm configurado a experiência moderna. 0 campo da comunicação concentra-se, então, em certos tipos de problemas relacionados ao modo pelo qual a mediatização da sociedade apresenta-se como organizadora de certos processos interacionais de referência (BRAGA, 2006, FERREIRA, 2007).

Essa centralidade da experiência humana, mesmo que mediatizada, na identificação de problemas comunicacionais tem enfrentado uma série de objeções. A origem delas pode ser encontrada na teoria da informação e na cibernética e em suas reconfigurações contemporâneas presentes nos estudos sobre a materialidade da comunicação. Em alguns casos, essas abordagens integram-se, de forma direta, a determinadas reflexões sobre o póshumanismo e a teoria do ator-rede - que não serão desenvolvidas aqui.

Vamos utilizar como referência neste debate um artigo de Felinto (2011) no qual o autor destaca a dificuldade que a Teoria dos Media ou Media Studies tem para encontrar um lugar, ou melhor, para tornar-se reconhecida como formuladora de questões epistemológicas relevantes para o campo da comunicação. No caso, ele está citando diretamente 0 GT Epistemologias $d a$ Comunicação da Compós.

Como referência na construção desses problemas epistemológicos relevantes, citados por Felinto, estão o trabalho de Friedrich Kittler e a influência que recebe de quatro grandes pensadores contemporâneos: Claude E. Shannon, Marshall McLuhan, Michel Foucault e Jacques Lacan. Quase todos, de uma maneira ou de outra, exerceram forte influência nos estudos no campo da comunicação. Entre eles, vamos nos concentrar nesse retorno de uma figura não muito grata em nosso campo: Claude E. Shannon, que, ao lado de Warren Weaver, foi responsável pela criação e divulgação da teoria da informação ou teoria matemática da comunicação. 
Mas, antes de dar continuidade à análise desse retorno, precisamos reconhecer que, no centro do debate contemporâneo sobre a sociedade mediatizada, as questões levantadas por Felinto merecem cuidadosa atenção. A presença de Kittler, Ernst, Gumbrecht e Manovich, entre outros, nesse debate (HANSEN, 2010) é a grande responsável por isso.

Essa ênfase em uma abordagem póshermenêutica é relevante e merece cuidadosa atenção, pois a própria concepção daquilo que pode ser chamado de humano não é um dado natural, mas produto de uma construção histórica (RÜDIGER 2009, 2011). A própria associação entre abordagens pós-hermenêuticas e abordagens pós-humanistas precisa ser feita com muito cuidado, pois, como destaca Liesen, não se trata de uma superação da hermenêutica, mas da exposição de elementos que não são analisados por ela ou questões que vêm sendo tratadas de modo insatisfatório no entendimento do processo de comunicação. É preciso atenção para 0 "que está além ou aquém do sentido, da ordem simbólica ou da estrutura das diferenças" (LIESEN, 2015).

A ideia de que estamos diante de uma medial turn, que Felinto compartilha com Stefan Münker, também merece destaque e pode desdobrar-se em um novo tipo de problema: 0 que há de novo na medialidade dessas novas mídias digitais que não se encontrava no novo das, então, novas mídias analógicas?
Como já foi destacado de forma clara e precisa por Albuquerque (2002), o desenvolvimento das novas mídias - como ativadora de ambientes ou ambiências tecnologicamente mediadas - nos coloca diante de um tipo de meio de comunicação muito particular.

Na verdade, estamos diante de um metameio que deve tornar-se inteligível para os seus usuários humanos, mas que, para fazê-lo, é obrigado a assumir, antes, uma forma "inteligível" para um agente não humano - na forma de um código, um algoritmo ou um programa (JOHNSON, 2001; LÉVY, 2006; MANOVICH, 2001, 2013). Manovich (2001) enfatiza, portanto, que a mediação da experiência humana assume um novo lugar na configuração complexa entre a chamada camada cultural e a camada computacional dessa nova mídia ou metamedia.

Baseado nos apontamentos de Finnemann, Albuquerque (2002) destaca a articulação de três elementos funcionais na existência dessas novas mídias ou daquilo que, também, foi chamado de comunicação mediada por computador: 1) um sistema binário de notação, 2) uma sintaxe algorítmica e 3) programas. A capacidade de aproximar essa lógica computacional do entendimento humano fica a cargo das interfaces.

As questões que nos orientam nessa discussão seguem, portanto, nessa direção. Para isso, retomamos alguns conhecidos princípios da 
teoria da informação, desenvolvida por Claude

E. Shannon, e a resistência que os pesquisadores em comunicação - categoria na qual estamos incluídos - demonstra com relação a ela.

Antes de dar início a essa tarefa, cabe, ainda, uma reflexão importante. É preciso ressaltar que algumas das tentativas de abordagem da relação entre as teorias da comunicação e as teorias $d a$ cibercultura seguem caminhos diferentes dos pretendidos aqui.

Martino (2013) faz um rápido, preciso e didático balanço dessas abordagens. No entanto, são as perguntas que propõe ao fim de cada mapeamento do debate que se mostram desafiadoras. Entre as principais, destacamos: com 0 aparecimento das teorias da cibercultura, seria possível criar uma espécie de tabula rasa dos estudos de comunicação - 0 aparecimento de um "grau zero" da pesquisa? Teorias da cibercultura não são Teorias da comunicação? Há algo de novo nesse suporte físico - 0 computador e os dispositivos digitais - que produz uma ruptura nas formas de abordagem dos fenômenos comunicacionais, tornando irreconciliável a sua integração ao domínio das teorias da comunicação?

Seria importante pensar, ainda, em retrospectiva. Se existe uma Teoria das Mídias Digitais, faria sentido transformar os livros de Teorias $d a$ Comunicação em Teoria das Mídias Analógicas? Teria sentido um compêndio de textos clássicos em mídias analógicas e digitais? Poderíamos falar de Cultura das Mídias ou Ecologia Pluralista da Comunicação, como propôs uma vez Santaella (2003, 2010)? E o que dizer de compêndios com o título: Cyberculture, Brodcastculture ou Printculture?

Para os Mass media culture, qual seria o equivalente? Interactive media culture? Poderíamos falar de modo geral de cultura de interfaces e, no caso das novas mídias, em cultura do software ou cultura do algoritmo? 0 termo interface poderia ser generalizado para mídias analógicas? Quais seriam as consequências disso em termos epistemológicos?

Media Studies seria abrangente o suficiente? Media and Communication Studies? New Media and Communication Studies? Seria 0 caso de classificar todos esses estudos como Teoria dos media e das mediações? Ou, ainda: Mediações e Midiatizações? (JANNOTI, MATTOS, JACKS, 2012).

Paul A. Mayer, por exemplo, no compêndio Computer Media and Communication, vislumbra um novo campo emergente: os Computermediated Studies (MAYER, 1999). Ao falar da diferença entre estudos da cibercultura e estudo das novas mídias, Manovich segue outro caminho e posiciona-se da seguinte forma:

Para começar, podemos distinguir as novas mídias e a cibercultura. A meu ver, elas representam dois campos de pesquisa distintos. Eu definiria a cibercultura como o estudo dos vá- 
rios fenômenos sociais associados à internet $\mathrm{e}$ outras novas formas de comunicação em rede (...) Observe que a ênfase está nos fenômenos sociais: a cibercultura não lida diretamente com novos objetos culturais capacitados pelas tecnologias de comunicação em rede [grifo nosso]. 0 estudo desses objetos é 0 domínio das novas mídias. Além disso, as novas mídias ocupam-se de objetos e paradigmas culturais capacitados por todas as formas de computação, não apenas pela rede. (MANOVICH, 2005 p. 27)

A questão principal continua: os estudos de cibercultura e os estudos das novas mídias podem ou não ser pensados a partir de uma Teoria Geral da Comunicação? A cibercultura seria um subcampo dos estudos sobre as novas mídias? As novas mídias seriam um subcampo dos Media Studies?

Albuquerque (2002), por exemplo, ao falar da imprensa, refere-se a ela como reprodução técnica a partir de matrizes. Seria esse um modelo de definição a partir dos meios? Por exemplo: processos de produção e reprodução técnica a partir de sistemas elétricos e ondas eletromagnéticas ou produção e reprodução técnica a partir de softwares? Deveríamos falar de comunicação mediada pelos meios impressos ou comunicação mediada por rádio e TV (radiodifusão) ou comunicação mediada por computador? A comunicação mediada por computador será capaz de reconfigurar a análise de todos os outros tipos de comunicação mediadas tecnicamente?

Galloway (2004) - em suas reflexões sobre os protocolos - e Manovich $(2001,2013)$ - sobre os
Software Studies ou Cultural Analytics - têm feito um enorme esforço para integrar os estudos orientados pela Ciência da Computação aos estudos em Ciências Humanas.

Embora uma boa parte desse caminho tenha sido desenvolvida a partir de referências a McLuhan, Foucault, Deleuze e Derrida, há uma questãochave que precisa ser enfrentada: o campo da comunicação não poderá ignorar por muito tempo esse novo conjunto de reflexões. De certo modo, ele já tem inspirado novos campos de reflexão independentes.

Portanto, se for adequada a proposta de controle da dispersão no campo por meio do desentranhamento do fenômeno comunicacional (BRAGA, 2006), poderíamos propor a seguinte questão: como lidar com esse desentranhamento em uma área - a ciência da computação - que tem uma genealogia muito particular e está distante das referências que conhecemos nas ciências humanas? De que forma poderíamos - nós, das Ciências Humanas - reformular diversos tipos de problemas propostos por esses estudos?

Na verdade, parece que são "eles" que estão desentranhando o fenômeno informacional dos mais diversos âmbitos e disciplinas, inclusive dos fenômenos comunicacionais.

Quando Manovich (2001) anunciou que estamos vivendo, cada vez mais, em um mundo marcado pela convergência entre duas grandes áreas - 
os meios de comunicação e os computadores - que se desenvolveram paralelamente ao longo das transformações do mundo moderno ocidental, talvez não tenhamos dado a devida atenção ao significado disso. Quando ocorre a convergência entre esses dois tipos específicos de desenvolvimentos sociotécnicos fundamentais para o mundo moderno, não se trata apenas de um encontro, mas de uma profunda reconfiguração - inclusive no que diz respeito às questões epistemológicas que esse processo traz.

\section{Claude E. Shannon revisited}

Roszak (1988) observa que, nos anos que antecederam a Segunda Guerra Mundial, a palavra informação não era tratada com tanta atenção. A coleção de palavras-chave sobre Cultura e Sociedade, elaborada por Raymond Williams, por exemplo, não faz nenhuma referência a ela, uma vez que o período abordado na obra estava concentrado entre a Revolução Industrial e 0 fim da Segunda Guerra. Na edição brasileira, organizada por Marcos Dantas, ela é incluída (WILLIAMS, 2007) e, neste caso, é possível verificar a modificação de sentido pela qual passa a partir dos anos 1940 .

Williams talvez não tenha dado a devida atenção a essa considerável mudança trazida pela publicação da Teoria Matemática da Comunicação, de Claude E. Shannon, em 1948. Hoje, vemos uma retomada das referências ao matemático e engenheiro dos Laboratórios Bell em uma boa parte dos estudos sobre a materialidade da comunicação e os Software Studies.

Para Nicholas Gane (2005), por exemplo, o materialismo pós-humanista radical de Friedrich Kittler enfatiza que os processos de comunicação dependem, no fundo, de sua materialidade, ou seja, dos dispositivos materiais de produção, processamento, distribuição e armazenamento de informação encontrados na sociedade. 0 que está em jogo não são, necessariamente, problemas de ordem semântica ou pragmática, ou seja, processos humanos de mediação. Kittler (1996) trabalha com dois conceitos importantes: redes de discurso (discourse networks) e seus sistemas de inscrição. Discourse networks foi definida como uma rede de tecnologias e instituições que permitem a uma cultura qualquer selecionar, guardar e processar dados considerados relevantes. Segundo Kittler, o fundamento desse novo modo de pensar a materialidade dos dispositivos comunicacionais está relacionado aos avanços produzidos pela Teoria da Informação, de Claude E. Shannon (ERMITAGE, 2006).

Trata-se de uma observação relevante para os pesquisadores no campo da comunicação, pois as críticas que a Teoria da Informação sofreu neste campo geraram uma verdadeira Shannonfobia. Toda vez que se apresentava a teoria da informação em um manual de teoria da comunicação era com 0 seguinte propósito: mostrar como o sistema linear era extremamente equivocado e reducionista para se pensar a comunicação humana. 
Entretanto, quando nos deparamos com autores que foram influenciados ou tiveram sua formação na área da computação, a situação se inverte. Johnson (2003), por exemplo, tece uma série de elogios aos trabalhos de Claude Shannon e o modo pelo qual construiu sua teoria. 0 matemático chega a ser apontado como um dos fundadores da teoria da complexidade.

Pode parecer estranho, mas a maneira como a teoria da informação é vista a partir das teorias da comunicação contemporâneas não parece em nada com a ideia de complexidade. Na verdade, foram várias as lutas para retirá-la de sua condição hegemônica no campo, justamente, por não parecer nada complexa.

Como "teoria da comunicação", o esquema gráfico que a representava era linear e relativamente simples: da fonte de informação sai a mensagem. Ela passa por um transmissor (codificador), 0 qual a transforma em um sinal. Esse sinal passa por um canal, que tem como função conduzilo a um receptor-decodificador. 0 receptor (decodificador), por sua vez, tem por função transformar o sinal em mensagem compreensível para um destinatário.

Shannon, como matemático e engenheiro, observou que a passagem pelo canal era um momento crítico do processo de transmissão. Era nesse momento que aparecia um tipo de fenômeno que incomodava demasiadamente os engenheiros: o ruído. 0 ruído aumentava consideravelmente a quantidade de informação - não desejada - no sinal enviado, o que dificultava o procedimento de decodificação da mensagem.

Nessa teoria, informação é uma medida de incerteza, uma questão de probabilidade. Trata-se de uma escolha possível em meio a tantas outras disponíveis. Portanto, ela não é um problema semântico nem pragmático. $O$ que está sendo transmitido é, na verdade, irrelevante, pois 0 que importa é o quanto de informação que se tem (PELLEGRINI, 2009, SERRA, 2007). Quanto maior a incerteza, maior é a entropia, e quanto maior a entropia, maior a informação trazida pela mensagem. Uma mensagem previsível teria uma quantidade de informação muito reduzida.

Um dos processos que atenua sensivelmente a incerteza e a imprevisibilidade da informação é $a$ redundância - um aumento da previsibilidade, ou seja, a capacidade de identificar, entre todas as possibilidades dadas, a fração da mensagem que não é necessária e que pode ser descartada. Ela contribui no processo de identificação de padrões e é fundamental para a redução da incerteza.

Warren Weaver, que contribuiu para a popularização da teoria matemática $d a$ informação (conhecida como modelo de Shannon \&Weaver), observa que questões semânticas, relacionadas à interpretação do significado pelo receptor, e questões pragmáticas, que dizem respeito à influência ou eficácia de uma mensagem recebida, não são relevantes para essa 
teoria. 0 que interessa são os problemas técnicos relacionados à produção, ao armazenamento e à transferência de informações de um emissor a um receptor. Ela "não se refere ao que você efetivamente diz, mas ao que poderia dizer, isto é: a informação é uma medida de sua liberdade de escolha quando seleciona uma mensagem" (WEAVER, 1978 p. 28).

Informação, ruído e entropia - aumento da incerteza ou da liberdade de escolha - caminham juntos. Weaver adverte: cuidado com a "armadilha semântica" que a palavra informação carrega! E é ele mesmo quem chama a atenção para 0 estranhamento produzido pela nova teoria:

\begin{abstract}
0 conceito de informação desenvolvido nesta teoria parece, à primeira vista, decepcionante $\mathrm{e}$ bizarro; decepcionante porque não tem nada a ver com significado e bizarro porque não lida com uma mensagem única, e sim com o caráter estatístico de todo um conjunto de mensagens. Bizarro, também, nesses termos estatísticos, as palavras informação e incerteza estão associadas. (WEAVER, 1978 p. 35)
\end{abstract}

Mas, por mais estranho que possa parecer, foi essa concepção linear do processo que marcou os estudos de comunicação por um bom tempo. Todavia, a ideia de que a teoria matemática da comunicação não lidava com problemas semânticos ou pragmáticos era motivo de grande desconforto no campo, pois tratava-se de uma linguagem de máquinas e não da linguagem humana.

Essa noção moderna de informação demandava, consequentemente, uma mudança significativa na maneira de entendê-la: 1) ao separar forma e sentido; 2) ao concentrar-se na transmissão de mensagens por meio de sinais elétricos e 3) ao se vincular a pesquisas matemáticas sobre 0 desenvolvimento de algoritmos e da criptografia (BRETON, 1991 p.48).

A descoberta de que sinais elétricos poderiam ser traduzidos em termos de funções matemáticas trouxe inumeráveis consequências para a comunicação no mundo moderno. 0 controle alcançado pelo conhecimento das ondas eletromagnéticas e de seu processo de transmissão permitiu o desenvolvimento de uma nova rede de comunicações a distância.

Essa ampliação do sistema de transmissão de mensagens - devido ao aperfeiçoamento da noção de sinal - aumentou, também, a preocupação com 0 acesso público ao conteúdo daquilo que era transmitido. Essas novas condições materiais de publicização das mensagens acabavam por gerar um novo tipo de problema político, pois tornavase cada vez mais difícil manter em segredo 0 conteúdo de certas mensagens. Por isso, essas transformações irão servir, também, de base para 0 aperfeiçoamento das técnicas de cifragem e decifragem - criptográficas.

Shannon aparece, novamente, como um pesquisador fundamental nessa área, ao desenvolver uma medida de informação fundamental para o futuro da computação: 0 BIT (Binary digIT): "a quantidade de informação 
contida na escolha elementar entre duas possibilidades igualmente prováveis" (BRETON, 1991 p. 53). É importante constatar que as primeiras formulações de sistemas binários foram propostas por Leibniz justamente para lidar com problemas de criptografia. A álgebra de Boole e 0 conceito de máquina universal de Turing contribuirão também para o desenvolvimento dos princípios da computação moderna.

Como já foi dito, Shannon destacou-se como matemático por seus trabalhos com criptografia para 0 governo norte-americano no período da Segunda Guerra Mundial. Ele desenvolveu seus estudos nos famosos Laboratórios Bell, o lugar onde teve um breve contato com uma outra figura quase mítica da matemática e da computação: 0 inglês Alan Turing. Embora cada um deles estivesse envolvido em projetos secretos, ou seja, marcados por forte sigilo, nesse encontro foi possível falar de suas experiências com a criptografia (GLEICK, 2013). Além disso, a contribuição de Shannon para o entendimento dos processos de compressão de dados por meio de algoritmos é considerada fundamental, hoje, para o compartilhamento de música e de vídeo por streaming (PELLEGRINI,2009).

Para Striphas (2015), Shannon não desenvolveu, de fato, uma teoria matemática da comunicação. 0 que ele criou foram os fundamentos de uma teoria algorítmica da informação. Com isso, suas pesquisas anunciaram a função que os algoritmos passariam a ter no final do século XX.

\section{0 sonho cibernético de Wiener}

Na Segunda Guerra Mundial, o trabalho de Wiener com a "programação" dos sistemas de artilharia antiaérea dos Aliados - controle automático da direção do tiro rumo a um alvo em alta velocidade como um avião, por exemplo - fez com que ele se envolvesse, cada vez mais, com 0 estudo de mecanismos complexos de integração entre humanos e máquinas. São os chamados estudos sobre os servomecanismos.

Essa capacidade que homens, máquinas e animais têm para ajustar 0 seu comportamento às condições encontradas no ambiente levou-o a descobrir um fator que acompanha qualquer ação complexa - os processos de realimentação ou feedback. Organismos ou sistemas complexos, por exemplo, são capazes de corrigir a sua ação a partir de informações que recolhem do ambiente. Para Wiener, tal como para Shannon, a entropia continua sendo um problema, mas ela não é enfrentada apenas com mecanismos de redundância. 0 princípio que orienta a ação em homens, animais e máquinas complexas é um só: a comunicação e o processo de realimentação. Ao contrário de Shannon, o modelo de Wiener (1968) não é mais linear. 0 agente (homem ou máquina) é orientado por um propósito específico (atingir um avião, pegar um copo d'água, ligar para alguém, etc.), porém, seu processo de orientação é circular, isto é, ele é orientado por retroalimentação constante. 
Norbert Wiener, matemático ligado ao MIT, será 0 responsável por um conjunto de transformações no modo pelo qual pensamos a relação entre homens e máquinas a partir de meados dos anos 1940. 0 projeto utópico construído por ele a partir dessas ideias sustenta-se em três pontos: 1) um modelo de sociedade ideal - em que as guerras e os conflitos não levassem o planeta à entropia; 2) uma nova definição antropológica de homem - o homo communicans, e 3) a comunicação como um valor fundamental para se entender a vida. 0 que chama mais a atenção nesse projeto é sua visão do ser humano como “... um ser sem interioridade e sem corpo, que vive em uma sociedade sem segredos; um ser por inteiro voltado para 0 social, que não existe se não através da informação e da permuta, numa sociedade tornada transparente graças às novas 'máquinas de comunicar" (BRETON, 1992 p. 46).

0 inimigo não é mais um ser humano. 0 inimigo é o ruído - 0 risco da entropia -, a qual deve ser combatida com a circulação generalizada de informações. 0 homem constitui-se em meio a máquinas inteligentes - suas parceiras - no processo de autorregulação e de controle de sua própria vida (KIM, 2004).

Na cibernética, não é mais o corpo biológico que está na base da existência social. 0 que 0 representa é a sua natureza informacional. Na verdade, os problemas relacionados ao biológico passam a ser pensados como problemas comunicacionais também.
Para entender as consequências desses pressupostos, é preciso que se preste atenção na maneira pela qual Wiener pensava a possibilidade de transmissão de sons, imagens e... pessoas! Para o matemático, o que se transmite no rádio são modelos (ou modulações) de som e 0 que se transmite na televisão são modulações de luminosidade. Uma modulação de seres humanos com suas lembranças e interações com 0 ambiente seria possível também. A incapacidade de telegrafar uma modulação humana de um lugar para outro devia-se, muito mais, a obstáculos técnicos. Ela não resultava de qualquer impossibilidade da ideia em si mesma (BRETON, 1992).

Uma vez dada essa condição informacional da experiência humana, é relativamente compreensível que autores como Kittler (FELINTO, 2011, GANE, 2005) enfatizem a materialidade dos meios como os modos de registro, processamento, distribuição e armazenamento dessa humanidade, pois ela depende da própria medialidade da experiência humana (BASTOS, 2012).

Galloway \& Thacker (2007) constatam que a questão fundamental que se coloca no entendimento dessa experiência não está na pergunta: Quem eu sou? Para os autores, ela devia ser feita de outra forma: De que modo um "eu" tornou-se essencial para certo tipo de experiência cultural a partir dos agenciamentos, dos dispositivos e da materialidade de sua comunicação? 
Para se ter uma ideia da influência que a teoria da informação e a cibernética tiveram - não apenas com seus modelos matemáticos, mas como produtores de metáforas para um novo mundo -, vale a pena prestar atenção nesta reflexão de Geertz a respeito da particularidade da experiência humana:

“... a cultura não é mais vista como complexos padrões concretos de comportamentos - costumes, usos, tradições, feixes de hábitos - como tem sido até agora, mas como um conjunto de mecanismos de controle - planos, receitas, regras, instruções (o que os engenheiros da computação chamam de 'programas') para governar o comportamento (GEERTZ, 1989 p. 56)."

Essa ideia não parece contraditória com sua visão de que 0 homem é um animal amarrado a uma teia de significados que ele mesmo teceu - a Cultura - e que a Antropologia seria, então, uma ciência interpretativa. Esse posicionamento da questão poderia nos levar a indagar se Geertz não estaria pensando, de alguma forma, em algo como a existência de algoritmos culturais.

Diante desse quadro, Lafontaine (2007) sustenta que o mundo contemporâneo está cada vez mais parecido com 0 estranho mundo sonhado pelo pensamento cibernético: um mundo sem fronteiras, inteiramente tomado por processos de comunicação - transformados, agora, em suporte para o processamento de informação -, no qual as fronteiras entre homens e máquinas começam a ser abolidas.

\section{Software - Algoritmos - Comunicação}

Para Manovich (2001), estamos diante de um acontecimento histórico significativo representado pela confluência entre as tecnologias de comunicação (imprensa e broadcasting) e os computadores - os quais, até então, vinham se desenvolvendo paralelamente. Ambas foram fundamentais para o desenvolvimento das chamadas "sociedades de massa" modernas (BENIGER, 1986).

Foi somente no final do século XX que essas duas áreas começaram a "convergir" de maneira significativa, criando as condições para 0 desenvolvimento do que viria a ser chamado de novas mídias.

Para entendermos o significado dessa transformação no processo de armazenamento, processamento e distribuição da informação, ou seja, na sua materialidade, é preciso identificar cinco princípios que caracterizam o "novo" nessas novas mídias digitais.

Em primeiro lugar, as formas simbólicas e culturais humanas são convertidas em representação numérica e tornam-se computáveis - binárias. 0s objetos das novas mídias são representados matematicamente e podem ser manipulados por algoritmos. Sua sintaxe é produzida a partir de uma estrutura modular (que permite modificações por camadas ou blocos independentes de 
dados). Graças a essas novas condições, ela funciona por processos automatizados (os quais não dependem necessariamente de uma intervenção humana direta, uma vez que são produzidos por algoritmos), marcados pela variabilidade (capacidade de ação responsiva, objetos adaptáveis a múltiplas plataformas e a múltiplos tipos de escalas de aproximação) e adequada a processos de transcodificação (que são as mudanças dos padrões culturais de representação a partir das condições particulares de representação numérica dos sistemas computacionais).

Manovich $(2005,2013)$ destaca que o foco de seus estudos são os softwares culturais, a cola invisível, que liga comunicação, escrita, representação, análise, simulação, memória, visão, interação, ou seja, esse conjunto de atividades associadas à Cultura. Com as novas mídias, essas camadas de software permeiam todas as atividades do mundo contemporâneo. Na verdade, o software - como materialidade - estabelece a mediação entre duas camadas fundamentais da experiência contemporânea: a camada cultural e a computacional.

Precisamos entender que aquilo que é chamado de ciberespaço não compreende apenas os meios materiais de telecomunicação, mensagens e seres humanos; ele é povoado por "seres estranhos, meio textos, meio máquinas, meio atores, meio cenários: os programas" (LÉVY, 1999 p. 41). Muitos desses programas podem ser chamados também de agentes (JOHNSON, 2001) e todos baseiam-se em códigos, protocolos, algoritmos.

Há sempre algo de impenetrável nos algoritmos, haja vista que são programados para funcionar sem intervenção humana e para lidar com uma estrutura de dados de tal dimensão que dificilmente possibilita controle por parte de seres humanos. A única maneira de acompanhá-los é por meio de outras ferramentas algorítmicas (GILLESPIE, 2012).

Striphas (2015) constata, ainda, que os princípios de autoridade ou os critérios de relevância - que marcavam as relações sociais e que orientavam determinados tipos de ordem social, relações de autoridade, dominação e poder - estão sendo lentamente transferidos para os algoritmos, sem que isso mereça uma maior análise e atenção por parte dos pesquisadores do campo da comunicação. Os algoritmos aparecem, então, como essa nova espécie de mediadores automatizados, criados para nos proteger objetivamente da entropia-desordem do mundo contemporâneo. Como foi visto anteriormente, trata-se de uma preocupação típica da cibernética wieneriana.

0 que torna essa questão ainda mais relevante é que a sua presença quase nunca é evidente, o que faz com que Cheney-Lippold trate os softwares, os algoritmos e os protocolos como objetos culturais incorporados e integrados aos sistemas sociais. Eles seriam os dispositivos 
agenciadores de uma soft biopolitic (CHENEY-

LIPPOLD, 2011; SILVEIRA, 2009).

Como objetos culturais e como identificadores de critérios de relevância pública da informação, Gillespie (2012) identifica seis dimensões dos algoritmos que merecem nossa atenção.

Primeiro, encontramos os padrões de inclusão ou exclusão de dados que podem ser submetidos à forma algorítmica, pois, antes de serem analisados, os dados precisam ser coletados de um certo modo e precisam ser "legíveis" para os softwares.

Existem, ainda, os ciclos de antecipação, os quais permitem antecipar ou criar algum grau de previsão com relação aos padrões encontrados nas redes. 0 acesso total aos dados pode gerar um verdadeiro banco de identificação de condutas digitais (digital fingerprints) - ou o que pode ser chamado de uma identidade algorítmica.

No caso das avaliações de relevância, precisamos lembrar que a noção de relevância é quase sempre muito fluida e que os valores utilizados como referência para o funcionamento do algoritmo podem ser modificados muito facilmente, de modo quase instantâneo e de maneira praticamente invisível.

Encontramos, também, a promessa de uma objetividade algorítmica: 0 modo pelo qual 0 algoritmo é identificado com uma pretensa garantia de imparcialidade. Sua relevância pública passa a ser construída a partir de sua pretensa função técnica, que o legitimaria como um poderoso estabilizador da confiança.

Uma outra dimensão dos algoritmos é o seu enredamento nas práticas sociais, ou seja, a maneira como os usuários, consciente ou inconscientemente, adaptam suas condutas a partir da lógica algorítmica ou, por outro lado, a submetem a um questionamento político.

Temos, por fim, a produção de um público calculável, ou seja, os algoritmos criam um tipo de perfil de usuários baseado em pretensos comportamentos digitais comuns (networked publics). Não há, ainda, uma teoria ou um conjunto de conceitos adequados para se definir em que nível atuam essas formações algorítmicas.

A partir dessas reflexões, torna-se possível pensar uma análise da experiência humana a partir da materialidade da comunicação, ou melhor, pensar a medialidade como parte constitutiva dessa própria experiência. A questão que se coloca, agora, é a de entender em meio a que tipo de materialidades nos constituímos e como fazemos isso.

Se essas análises estiverem corretas, voltamos à nossa questão inicial. Como já foi ressaltado por Braga, o objeto da comunicação não são nem "coisas" nem "temas", mas um olhar específico que identifica processos comunicacionais - não importando muito se estamos falando de signos, mídias ou... softwares. 
Se 0 campo da comunicação deve concentrar-se no modo pelo qual a mediatização da sociedade apresenta-se como organizadora de certos processos interacionais de referência, como podemos pensar a materialidade desses seres estranhos - que são os softwares e a sua lógica algorítmica - nesses processos?

Os softwares (softwares culturais) seriam a base sobre a qual se levantam os processos interacionais de referência contemporâneos? Seriam eles da ordem comunicacional? Como integrar essa preocupação às Teorias da Comunicação?

\section{Referências}

ALBUQUERQUE, Afonso de. Os desafios epistemológicos da comunicação mediada por computador. Revista Fronteiras, Estudos

Midiáticos. São Leopoldo: Unisinos, 2002.

BASTOS, Marco Toledo. Medium, media, mediação e midiatização: a perspectiva germânica. In: Mediação \& Midiatização / Jeder Janotti Junior, Maria Ângela Mattos, Nilda Jacks, Orgs EDUFBA; Brasília : Compós, 2012.

\section{BENIGER, James. The Control Revolution:} Technological and Economic origins of the Information Society. Harvard University Press, 1986.

BRAGA, José Luiz. Constituição do campo da comunicação. Verso e Reverso, XXV n ${ }^{0} 58$, janeiroabril 2011 pp. 62-77.

Mediatização como processo interacional de referência. Animus - Revista interamericana de comunicação midiática v. $5 \mathrm{n}^{0} 2$ - julho-dez 2006.

2004. Os estudos de interface como espaço de construção do Campo da Comunicação.
Contracampo, n. 10/11 pp.219-235.

BRETON, Philip. História da Informática. São Paulo: Editora Unesp, 1991.

A Utopia da Comunicação.

Lisboa: Instituto Piaget, 1992

CHENEY-LIPPOLD, John. A new Algorithmic Identity soft biopolitics and the modulation of control. Theory, Culture \& Society v. 28 n. 6, 2011 pp. 164-181.

ERMITAGE, John. From Discourse Networks to Cultural Mathematics - An Interview with Friedrich A. Kittler. Theory, Cultura \& Society. v. 23 n. 7-8, 2006 pp 17-38.

FELINTO, Erick. Da Teoria da Comunicação às Teorias da Mídia ou, temperando a epistemologia com uma dose de cibercultura. Revista Eco-Pós, vol. 14 n. 12011 pp. 233-249.

Passeando no Labirinto: ensaio sobre as tecnologias e materialidades da comunicação. Porto Alegre: EDIPUCRS, 2006.

FERREIRA, Jairo. 2007. Midiatização: dispositivos, processos sociais e de comunicação. E-Compós, Compós, vol. 10, s. p.

FISKE, John. Introdução ao Estudo da

Comunicação. Lisboa: Asa. 1990.

FRANKLIN, Benjamin, BERGERMAN, Marcel. Algoritmos culturais: conceituação e aplicação em robótica - $4^{0} \mathrm{SBAI}$ - Simpósio Brasileiro de Automação Inteligente, São Paulo, SP, 08-10 de Setembro de 1999.

GALLOWAY, Alexander. Protocol: how control exists after decentralization. MIT Press, Cambridge, Massachusetts, London, 2004.

GALLOWAY, Alexander, THACKER, Eugene. The Exploit: a theory of Networks. University of Minnesota Press, 2007.

GANE, Nicholas. Radical Post-humanism: Friedrich Kittler and the Primacy od Technology. Theory, Culture 
\& Society, v. 22 n. 3, 2005 pp. 25-41.

GEERTZ, Clifford. A Interpretação das Culturas. Rio de Janeiro : LTC Editora, 1989.

GLEICK, James. A informação: uma história, uma teoria, uma enxurrada. São Paulo: Companhia das Letras, 2013.

HANCKE, Michael. Materialidade da Comunicação - um conceito para a Ciência da Comunicação?

Contracampo. № 14,2006 pp. 215-222

HANSEN, Mark B.N. New Media In: MITCHELL, W.J.T., HANSEN, Mark B.N. Critical Terms for Media Studies. The University of Chicago Press, Chicago London, 2010.

JANOTTI Jr., Jeder, MATTOS, Maria Ângela, JACKS, Nilda (orgs.) Mediação \& Mediatização. Prefácio: Adriano Duarte Rodrigues. - Salvador : EDUFBA; Brasília : Compós, 2012.

JOHNSON, Steven. Emergência: a vida integrada de formigas, cérebros, cidades e softwares. Rio de Janeiro: Jorge Zahar Editor, 2003.

.Cultura da Interface. Rio de

Janeiro: Jorge Zahar Editor, 2001.

KIM, Joon Ho. Cibernética, ciborgues e ciberespaço: notas sobre as origens da cibernética e sua reinvenção cultural. Horizontes Antropológicos, Porto Alegre, ano 10, no 21, p. 199-219, jan./jun. 2004 pp. 199-219.

KITTLER, Friedrich. The history of Communication Media. CTheory.net 30/07/1996 http://www.ctheory. net/articles.aspx?id=45\#bio (acessado em 20.01.2016).

LAFONTAINE, Céline. 0 império cibernético. Lisboa: Instituto Piaget, 2007.

LÉVY, Pierre. Tecnologias da Inteligência. Rio de Janeiro: Editora 34, 13. Reimpressão, 2006.

LIESEN, Maurício. Materialidades mediais. Notas sobre uma perspectiva pós-hermenêutica. Contracampo.

Niterói. v.33 nº 2, ago-nov 2015.

MANOVICH, Lev. Software Takes Command, New York: Bloomsbury Academic, 2013.

Novas mídias como tecnologia

e ideia: dez definições. In: LEÃO, Lucia. 0 chip e o

caleidoscópio: reflexões sobre as novas mídias. São Paulo: Ed. SENAC, 2005.

The Language of New Media.

Cambridge/Mass: MIT Press, 2001.

MARTINO, Luís Mauro Sá. Repensando a(s) teoria(s) da Cibercultura: articulações e tensões com as teorias da Comunicação - Questões Transversais - Revista de Epistemologias da Comunicação Vol. 1, n 2 , julho-dezembro/2013 pp. 92-99. Quatro ambivalências na teoria da comunicação. Revista Rumores. São Paulo, ed.8, julho- dezembro, 2010.

MAYER, Paul (org.) Computer Media and Communication: a Reader. Oxford (NY). Oxford University Press, 1999.

PELLEGRINI, Christian Hugo. 0 significado contemporâneo da teoria da matemática da comunicação. Caderno.Com. São Caetano do Sul, v.4, $\mathrm{n}^{0}$ 2, pp 11-23. $2^{0}$ semestre 2009.pp. 12-23.

ROSZAK, Theodor. 0 culto da informação: 0 culto dos computadores e a verdadeira arte de pensar. São Paulo: Brasiliense, 1988.

RÜDIGER, Francisco. Notas sobre o pós-humanismo. In: TRIVINHO, Eugênio (org.). Flagelos e horizontes do mundo em rede: política, estética e pensamento à sombra do pós-humano. Porto Alegre: Sulina, 2009. RÜDIGER, Francisco. As Teorias da Cibercultura. Porto Alegre: Sulina, 2011.

SANTAELLA, Lucia. Da cultura das mídias à cibercultura: 0 advento do pós-humano. Revista 
FAMECOS • Porto Alegre. № 22. Dezembro 2003, pp.

23-32.

\section{Ecologia Pluralista da}

Comunicação: conectividade, mobilidade, ubiquidade. São Paulo: Paulus, 2010.

SERRA, J. Paulo. Manual de Teorias da

Comunicação. Universidade da Beira Interior,

2007 (Labcom) http://www.livroslabcom.ubi.pt/

pdfs/20110824-serra_paulo_manual_teoria_

comunicacao.pdf (acessado em 12/02/2015).

SILVEIRA, Sergio Amadeu da. Novas dimensões da política: protocolos e códigos na esfera pública interconectada. Rev. Sociol. Polit. [online]. 2009, vol.17, n.34 pp.103-113.

STRIPAS, Ted. Algorithmic Culture. European Journal of Cultural Studies. V. $18 \mathrm{n}^{0}$ 4-5, 2015 pp. 395-412.

WEAVER, Warren. "A Teoria Matemática da Comunicação" In: COHN, Gabriel (org.) Comunicaçãa e Indústria Cultural. São Paulo: Companhia Editora Nacional, 1978.

WIENER, Norbert. Cibernética e Sociedade: o uso humano dos seres humanos. $2^{\mathrm{a}}$ ed. São Paulo: Cultrix, 1968.

WILLIAMS, Raymond. Palavras-Chave: um vocabulário de cultura e sociedade. São Paulo: Boitempo Editorial, 2007. 


\section{The strange world of information - and materiality - in the field of communication}

\section{Abstract}

The growing presence of studies focused on concepts such as materiality of communication has brought to the field of communication two very particular types of approach. In this paper, we focus on the specificity of new media and the reappearance of communication models based on Claude $\mathrm{E}$. Shannon's Information Theory and Norbert Wiener's cybernetics. The convergence of media technologies and digital computation - indicated by Manovich brought to the field of Communication a set of new research problems or the reorientation of classic problems that we have to face reflectively.

\section{Keywords}

Information. New Media. Materiality.

\section{El extraño mundo de la} información - y de la materialidad en el campo de la comunicación

\section{Resumen}

El aumento de la presencia de los estudios centrados en la importancia de la materialidad de la comunicación llevó al campo de la comunicación dos tipos de enfoque muy particulares. En este trabajo, nos centramos en la naturaleza específica de los nuevos medios y la reaparición de los modelos basados en la teoría de la información de Claude E. Shannon y la cibernética Norbert Wiener. La convergencia entre las tecnologías de la comunicación y la informática digital, indicado por Manovich, ha llevado al campo de la comunicación una serie de nuevos problemas de investigación o reorientación de los problemas clásicos que tendremos que observar reflexivamente.

\section{Palabras clave}

Información. Nuevos Medios. Materialidad. 


\section{Expediente}

A revista E-Compós é a publicação científica em formato eletrônico da Associação Nacional dos Programas de Pós-Graduação em Comunicação (Compós). Lançada em 2004, tem como principal finalidade difundir a produção acadêmica de pesquisadores da área de Comunicação, inseridos em instituições do Brasil e do exterior.

\section{E-COMPÓS I www.e-compos.org.br I E-ISSN 1808-2599}

Revista da Associação Nacional dos Programas de Pós-Graduação em Comunicação.

Brasília, v.20, n.1, jan./abr. 2017.

A identificação das edições, a partir de 2008, passa a ser volume anual com três números.

Indexada por Latindex I www.latindex.unam.mx

\section{CONSELHO EDITORIAL}

Alda Cristina Silva da Costa, Universidade Federal do Pará, Brasil Alfredo Luiz Paes de Oliveira Suppia, Universidade Estadual de Campinas, Brasil Álvaro Larangeira, Universidade Tuiuti do Paraná, Brasil Ana Carolina D. Escosteguy, Pontifícia Universidade Católica do Rio Grande do Sul, Brasil Ana Regina Barros Rego Leal, Universidade Federal do Piauí, Brasil Ana Carolina Rocha Pessôa Temer, Universidade Federal de Goiás, Brasil Andrea França, Pontifícia Universidade Católica do Rio de Janeiro, Brasil André Luiz Martins Lemos, Universidade Federal da Bahia, Brasil Angela Cristina Salgueiro Marques, Faculdade Cásper Libero, Brasil Ângela Freire Prysthon, Universidade Federal de Pernambuco, Brasil Antonio Carlos Hohlfeldt, Pontifícia Universidade Católica do Rio Grande do Sul, Brasil Arthur Ituassu, Pontifícia Universidade Católica do Rio de Janeiro, Brasil Bruno Campanella, Universidade Federal Fluminense, Brasil Cláudio Novaes Pinto Coelho, Faculdade Cásper Líbero, Brasil Carlos Eduardo Franciscato, Universidade Federal de Sergipe, Brasil Denise Tavares da Silva, Universidade Federal Fluminense, Brasil Eduardo Vicente, Universidade de São Paulo, Brasil Eliza Bachega Casadei, Escola Superior de Propaganda e Marketing - SP, Brasil Elizabeth Nicolau Saad Corrêa, Universidade de São Paulo, Brasil Erick Felinto de Oliveira, Universidade do Estado do Rio de Janeiro, Brasil Erly Vieira Júnior, Universidade Federal do Espirito Santo, Brasil Francisco de Assis, FIAM-FAAM Centro Universitário, Brasil Francisco Elinaldo Teixeira, Universidade Estadual de Campinas, Brasil Frederico de Mello Brandão Tavares, Universidade Federal de Ouro Preto, Brasil Gabriela Reinaldo, Universidade Federal do Ceará, Brasil Gilson Vieira Monteiro, Universidade Federal do Amazonas, Brasil Gustavo Daudt Fischer, Universidade do Vale do Rio dos Sinos, Brasil Igor Sacramento, Fundação Oswaldo Cruz, Brasil Itania Maria Mota Gomes, Universidade Federal da Bahia, Brasil Jiani Adriana Bonin, Universidade do Vale do Rio dos Sinos, Brasil José Afonso da Silva Junior, Universidade Federal de Pernambuco, Brasil
José Luiz Aidar Prado, Pontifícia Universidade Católica de São Paulo, Brasil Juçara Gorski Brittes, Universidade Federal de Ouro Preto, Brasil Laura Loguercio Cánepa, Universidade Anhembi Morumbi, Brasil Liziane Soares Guazina, Universidade de Brasilia, Brasil Luíza Mônica Assis da Silva, Universidade Católica de Brasília, Brasil Maria Ataide Malcher, Universidade Federal do Pará, Brasil Maria Elisabete Antonioli, Escola Superior de Propaganda e Marketing - SP, Brasil Maria das Graças Pinto Coelho, Universidade Federal do Rio Grande do Norte, Brasil Marcel Vieira Barreto Silva, Universidade Federal da Paraíba, Brasil Marcia Tondato, Escola Superior de Propaganda e Marketing, Brasil Marli Santos, Universidade Metodista de São Paulo, Brasil Márcio Souza Gonçalves, Universidade do Estado do Rio de Janeiro, Brasil Mauricio Mario Monteiro, Universidade Anhembi Morumbi, Brasil Mauricio Ribeiro da Silva, Universidade Paulista, Brasil Mauro de Souza Ventura, Universidade Estadual Paulista, Brasil Mayka Castellano, Universidade Federal Fluminense, Brasil Micael Maiolino Herschmann, Universidade Federal do Rio de Janeiro, Brasil Mozahir Salomão Bruck, Pontifícia Universidade Católica de Minas Gerais, Brasil Nísia Martins Rosario, Universidade Federal do Rio Grande do Sul, Brasil Potiguara Mendes Silveira Jr, Universidade Federal de Juiz de Fora, Brasil Raquel Ritter Longhi, Universidade Federal de Santa Catarina, Brasil Regiane Regina Ribeiro, Universidade Federal do Paraná, Brasil Roberto Elísio dos Santos, Universidade Municipal de São Caetano do Sul, Brasil Rodolfo Rorato Londero, Universidade Estadual de Londrina, Brasil Sérgio Luiz Gadini, Universidade Estadual de Ponta Grossa, Brasil Simone Maria Andrade Pereira de Sá, Universidade Federal Fluminense, Brasil Simone Maria Rocha, Universidade Federal de Minas Gerais, Brasil Suzana Reck Miranda, Universidade Federal de São Carlos, Brasil Tarcyanie Cajueiro Santos, Universidade de Sorocaba, Brasil Tatiana Oliveira Siciliano, Pontifícia Universidade Católica do Rio de Janeiro, Brasil Veneza Mayora Ronsini, Universidade Federal de Santa Maria, Brasil

\section{CONSELHO CIENTÍFICO}

Cristiane Freitas Gutfreind, Pontifícia Universidade Católica do Rio Grande do Sul, Brasil Eduardo Morettin, Universidade de São Paulo, Brasil

Felipe Costa Trotta, Universidade Federal Fluminense, Brasil Irene de Araújo Machado, Universidade de São Paulo, Brasil

\section{COMISSÃO EDITORIAL}

Eduardo Antonio de Jesus, Universidade Federal de Minas Gerais, Brasil Marco Antonio Roxo da Silva, Universidade Federal Fluminense, Brasil Osmar Gonçalves dos Reis Filho, Universidade Federal do Ceará, Brasil

\section{CONSULTORES AD HOC}

Kelly C. de Souza Prudencio, Universidade Federal do Paraná, Brasil Francisco P. Jamil A. Marques, Universidade Federal do Paraná, Brasil Tiago Quiroga F. Neto, Universidade de Brasília, Brasil

\section{EQUIPE TÉCNICA}

ASSISTENTE EDITORIAL Márcio Zanetti Negrini REVISÃO DE TEXTOS Press Revisão EDITORAÇÃO ELETRÔNICA Roka Estúdio IMAGEM DE CAPA Silas de Paula

\section{COMPÓS I www.compos.org.br}

Associação Nacional dos Programas de Pós-Graduação em Comunicação

Presidente

Edson Fernando Dalmonte

Programa de Pós-Graduação em Comunicação

e Cultura Contemporânea - UFBA

edsondalmonte@uol.com.br

Vice-presidente

Cristiane Freitas Gutfreind

Programa de Pós-Graduação em Comunicação Social - PUC-RS cristianefreitas@pucrs.br

Secretário-Geral

Rogério Ferraraz

Programa de Pós-Graduação em Comunicação

Universidade Anhembi Morumbi

rogerioferraraz@anhembimorumbi.edu.br

CONTATO I revistaecompos@gmail.com 